\title{
EPITAXIAL LATERAL OVERGROWTH OF GaN ON SiC AND SAPPHIRE SUBSTRATES
}

\author{
ZHONGHAI YU*, M.A.L. JOHNSON* , J.D. BROWN*, N.A. EL-MASRY ${ }^{* *}$, J. F. MUTH* , J.W. \\ COOK, JR. ${ }^{*}$, J.F. SCHETZINA*, K.W. HABERERN ${ }^{* * * *}$, H.S. KONG ${ }^{* * *}$, AND J.A. EDMOND ${ }^{* * * *}$ \\ Department of Physics, North Carolina State University, Raleigh NC 27695, \\ jan_schetzina@ncsu.edu \\ ** Department of Materials Science and Engineering, North Carolina State University, Raleigh \\ NC 27695 \\ *** Cree Research Inc, 4600 Silicon Drive, Durham NC 27703
}

Cite this article as: MRS Internet J. Nitride Semicond. Res. 4S1, G4.3 (1999)

\begin{abstract}
The epitaxial lateral overgrowth (ELO) process for $\mathrm{GaN}$ has been studied using $\mathrm{SiC}$ and sapphire substrates. Both MBE and MOVPE growth processes were employed in the study. The use of $\mathrm{SiO}_{2}$ versus $\mathrm{SiN}_{\mathrm{x}}$ insulator stripes was investigated using window/stripe widths ranging from $2 \mu \mathrm{m} / 4 \mu \mathrm{m}$ to $3 \mu \mathrm{m} / 15 \mu \mathrm{m}$. GaN film depositions were completed at temperatures ranging from $800{ }^{\circ} \mathrm{C}$ to $1120{ }^{\circ} \mathrm{C}$. Characterization experiments included RHEED, TEM, SEM and cathodolumenescence studies. The MBE growth experiments produced polycrystalline $\mathrm{GaN}$ over the insulator stripes even at deposition temperatures as high as $990{ }^{\circ} \mathrm{C}$. In contrast, MOVPE growth produced single-crystal GaN stripes with no observable threading dislocations.
\end{abstract}

\section{INTRODUCTION}

Growth of GaN and other III-V nitrides on mismatched substrates such as sapphire or SiC produces a columnar material consisting of many small hexagonal grains [1]. The individual grains have a distribution of tilt and rotation within the GaN film that gives rise to very large dislocation densities and broad x-ray rocking curves (300-400 arc sec). In spite of this high degree of disorder, there have been demonstrations of very bright blue and green LEDs and blue/violet laser diodes at Nichia Chemical [2-5] and elsewhere [6-9]. These light-emitting devices, all prepared by MOVPE, exhibit dislocation densities of $10^{9}-10^{10}$ per $\mathrm{cm}^{2}$ but function as very bright light emitters as though these internal disruptions to periodicity are virtually absent - perhaps due to some unknown passivation process associated with the MOVPE growth process itself.

Recently, however, there have been demonstrations of defect reduction in GaN layers grown on sapphire [10-16] and $\mathrm{SiC}$ [17-19] using an epitaxial lateral overgrowth (ELO) technique. The ELO technique is illustrated schematically in Fig. 2. First, a high quality 1-2 $\mu \mathrm{m}$ thick layer of $\mathrm{GaN}$ is grown by MOVPE. Next, standard deposition and photolithographic techniques are employed to prepare a set of parallel $\mathrm{SiO}_{2}$ stripes oriented along a [1 $\left.\overline{1} 00\right]$ GaN crystal direction separated by window areas which expose the underlying GaN. A second deposition of $\mathrm{GaN}$ onto this patterned substrate is then initiated. During the initial $\mathrm{GaN}$ growth, the $\mathrm{SiO}_{2}$ stripes function as non-wettable surfaces and no GaN deposition occurs on them. However, once the GaN film growth from the window stripes reaches the tops of the $\mathrm{SiO}_{2}$ stripes, epitaxial lateral overgrowth of GaN commences. The ELO process produces stripes of GaN (5-10 $\mu \mathrm{m}$ wide) over the original $\mathrm{SiO}_{2}$ stripes which display a remarkable reduction in dislocation density to $\leq 10^{6}$ per $\mathrm{cm}^{2}$. It is on these low-dislocation-density single-crystal GaN stripes that Nichia Chemical has 
produced laser diodes having very long $\mathrm{CW}$ lifetimes $(10,000 \mathrm{hrs})$ [20]. In this paper, the results of a systematic study of GaN/ELO on sapphire and $\mathrm{SiC}$ substrates are reported in which both MBE and MOVPE growth processes were employed.

\section{EXPERIMENTAL DETAILS}

MBE growth experiments were performed in an EPI 930 system using elemental Ga and active nitrogen generated within RF plasma sources. The system is equipped with three RF plasma sources which permit growth of $\mathrm{GaN}$ at temperatures up to $\sim 1000{ }^{\circ} \mathrm{C}$. The MOVPE growth experiments were carried out in a low pressure, vertical-flow, cold-wall reactor featuring high-speed substrate rotation. Both systems are equipped with optical pyrometers for substrate temperature measurements.

Pre-nucleated GaN/sapphire and GaN/SiC wafers prepared by MOVPE were used for all of the ELO experiments. These wafers were coated with $\sim 100 \mathrm{~nm}$ of either $\mathrm{SiO}_{2}$ or $\mathrm{SiN}_{\mathrm{x}}$ using a low temperature plasma process. Next, a mask set was employed to define a series of parallel insulator stripes along a $\mathrm{GaN}$ [1 $\overline{1} 00$ ] crystal direction separated by VIAs (windows) using standard photolithographic techniques. RIE was then used to remove the insulator $\left(\mathrm{SiO}_{2}\right.$ or $\mathrm{SiN}_{\mathrm{x}}$ ) from the window areas and expose the underlying parallel $\mathrm{GaN}$ stripes. Window/stripe widths ranging from $2 \mu \mathrm{m} / 4 \mu \mathrm{m}$ up to $3 \mu \mathrm{m} / 15 \mu \mathrm{m}$ were employed in the present study. The patterned wafers were then returned to the growth chambers where ELO growth of GaN was initiated. All GaN ELO layers were intentionally doped with $\mathrm{Si}\left(\sim 1 \times 10^{18}\right.$ electrons $\left./ \mathrm{cm}^{3}\right)$.

The GaN ELO samples were characterized using a JEOL JSM-6400 scanning electron microscope (SEM) equipped with a model SP13064-6400 digital scan generator (DSG). Digital electron microscope images are acquired by the DSG with the aid of a computer which takes control of the instrument's horizontal and vertical scan coils, acquires a video signal at each pixel, and forms a digital image. Image pixel densities of up to $2560 \times 1920$ pixels are then stored on computer as a high-resolution digital image. The SEM is also equipped with an Oxford Instruments Mono-CL cathodoluminescence (CL) accessory. With this unit it is possible to obtain spectral CL scans from $180 \mathrm{~nm}$ to $900 \mathrm{~nm}$. In addition, monochromatic CL images of samples under investigation can be obtained at any selected wavelength in this wavelength range. In the present study, digital CL images at $560 \mathrm{~nm}$ (deep level emission) and at $364 \mathrm{~nm}$ (band edge emission) were obtained for selected GaN ELO samples.

Vertical-cross-section transmission electron micrographs were also obtained for selected samples using a Topcon model 002B transmission electron microscope operating at $200 \mathrm{kV}$. The TEM micrographs were taken under two-beam conditions using the c-axis as the operating vector $[\mathrm{g}=(0002)]$.

\section{RESULTS AND DISCUSSION}

\section{MBE Growth Experiments}

MBE growth of GaN was completed at temperatures ranging from $800{ }^{\circ} \mathrm{C}$ up to $990{ }^{\circ} \mathrm{C}$ using multiple nitrogen plasma sources. All of these experiments produced similar results, as is illustrated schematically in Figure 1. It is seen from the SEM micrograph shown in the figure that the GaN film growth onto the insulator areas consists of small randomly oriented columnar structures. RHEED patterns consisted of a concentric ring pattern from the overgrowth regions superposed on a spotty pattern from the window areas. This behavior was observed for samples prepared over the entire range of temperatures investigated. These results indicate that MBE cannot be used to prepare low dislocation density GaN by the ELO technique. This is so, most 
likely, because of the limited range of temperatures available for MBE growth of GaN at present. The upper temperature for MBE film growth is limited by the availability of active nitrogen present in the process. Even by employing three active nitrogen plasma sources, the highest growth temperature that we were able to employ was about $990{ }^{\circ} \mathrm{C}$.

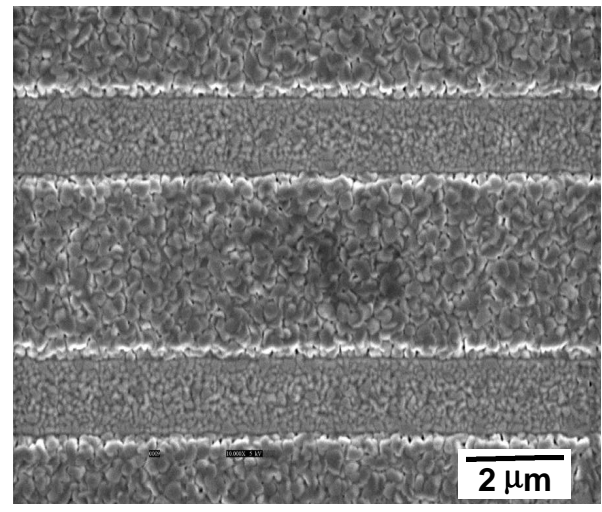

\section{Insulator \\ Window \\ Insulator \\ Window \\ Insulator}

Figure 1. SEM micrograph of MBE-grown GaN surface. RHEED studies imply polycrystalline growth over insulator areas for all MBE-grown samples.

\section{MOVPE Growth Experiments}

The MOVPE GaN/ELO growth experiments were performed at substrate temperatures ranging from $1050{ }^{\circ} \mathrm{C}$ up to $1120{ }^{\circ} \mathrm{C}$. During the initial GaN/ELO growth sequence by MOVPE, the insulator stripes function as non-wettable surfaces and no GaN deposition occurs on them. However, once the GaN film growth from the window stripes reaches the tops of the insulator stripes, epitaxial lateral overgrowth of $\mathrm{GaN}$ commences. All of the MOVPE experiments produced GaN single-crystal stripes over the insulator areas that showed a large reduction in threading dislocations. In many of the samples, no threading dislocations were observed in TEM vertical-cross-section studies. As the substrate temperature was increased, the growth morphology changed from ELO having inclined lateral sidewalls ( $\{1 \overline{1} 01\}$ planes) that spread rapidly towards the centers of the periodic insulator stripes to an epitaxial lateral growth featuring vertical sidewalls corresponding to $\{1 \overline{2} 0\}$ planes. This is illustrated by the SEM micrographs shown below in Figure 2 This type of morphology change with increasing growth temperature was observed when either $\mathrm{SiO}_{2}$ or $\mathrm{SiN}_{\mathrm{x}}$ insulator stripes were employed.

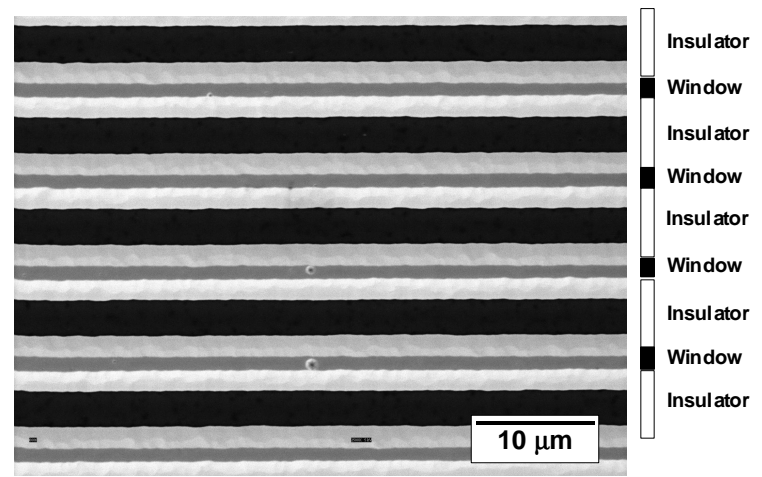

(a)

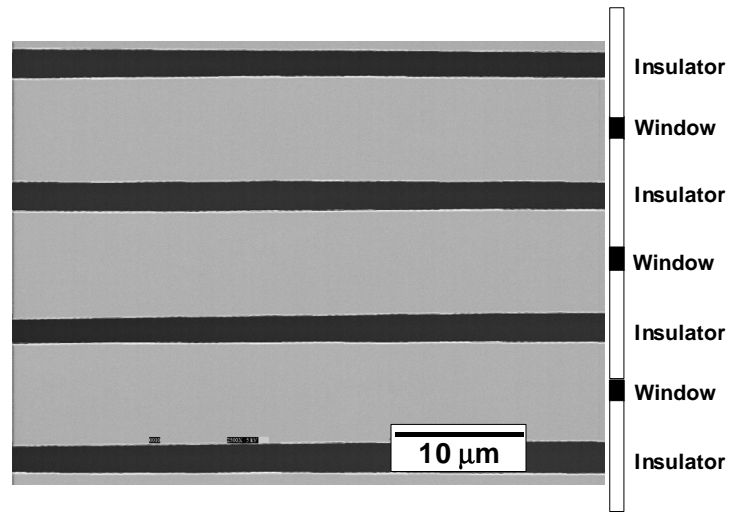

(b)

Figure 2. SEM photos showing GaN/ELO with (a) inclined lateral side-walls at low growth temperatures $\left(\sim 1050{ }^{\circ} \mathrm{C}\right)$ and $(\mathrm{b})$ vertical sidewalls at high growth temperatures $\left(\sim 1120{ }^{\circ} \mathrm{C}\right)$ 
Cathodoluminescence studies revealed a marked difference in the CL originating from the GaN growing in the window areas compared with that from the GaN/ELO. This is shown in Figure 3 where CL images and spectra are displayed. Figure 3(a) shows a panchromatic image

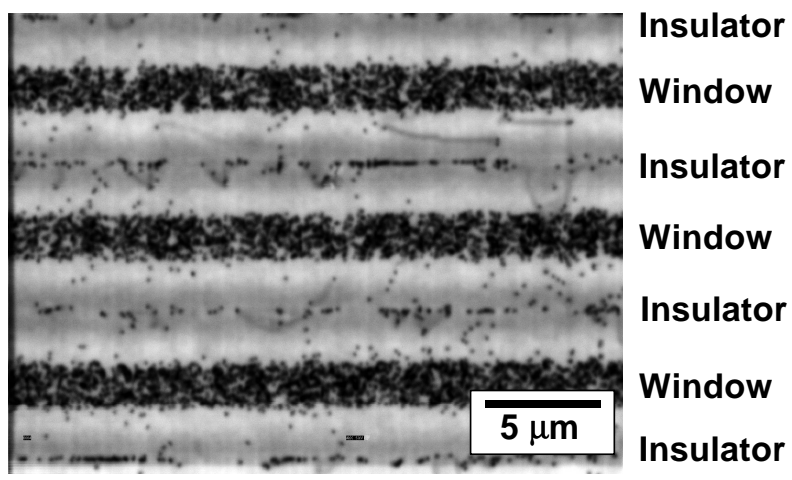

(a)

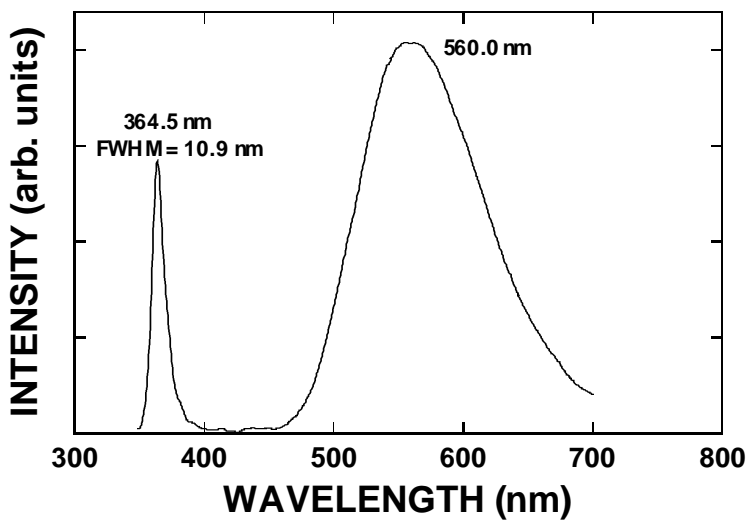

(b)

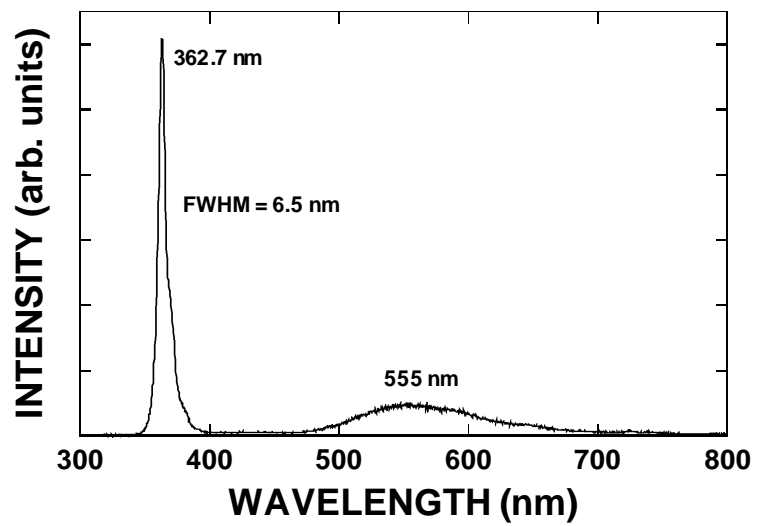

(c)

Figure 3. (a) Panchromatic CL image of a GaN/ELO surface. Light emission is more intense over insulator areas. Window CL is dominated by deep-level emission (b) whereas, near the center of the ELO stripes, the CL is primarily near bandedge emission (c).

of a GaN/ELO surface. It is seen that the window regions emit very little CL and this is largely deep level emission as shown in Figure 3(b). In contrast, the CL from the ELO regions is very bright and consists mainly of near bandedge emission as shown in Figure 3(c).

Figure 4 shows a vertical cross-section TEM image of a GaN/ELO sample. It is seen that the region beneath the insulator strip contains many threading dislocations (about $10^{10}$ per $\mathrm{cm}^{2}$ ). In contrast, the ELO above the insulator stripe contains no visible threading dislocations. Directly above the insulator stripe some misfit dislocations running parallel to the insulator surface are visible, but these diminish in density as the ELO process progresses. Threading dislocations continue to propagate upwards through the window regions as shown. For the growth parameters employed in this study, a lateral-to-vertical growth rate (LTVGR), as defined by Park et al. [15], of about 2.0 was obtained for all of the ELO growth experiments using both sapphire and $\mathrm{SiC}$ substrates.

The growth temperature employed for the ELO process had a profound effect on the ELO sidewalls as discussed above, and also on the void geometry that occurs near the centers of the insulator stripes where two adjacent GaN/ELO single crystal stripes coalesce. This is illustrated in Figure 5 where TEM micrographs obtained for ELO samples grown at $1080{ }^{\circ} \mathrm{C}$ and $1120{ }^{\circ} \mathrm{C}$, 


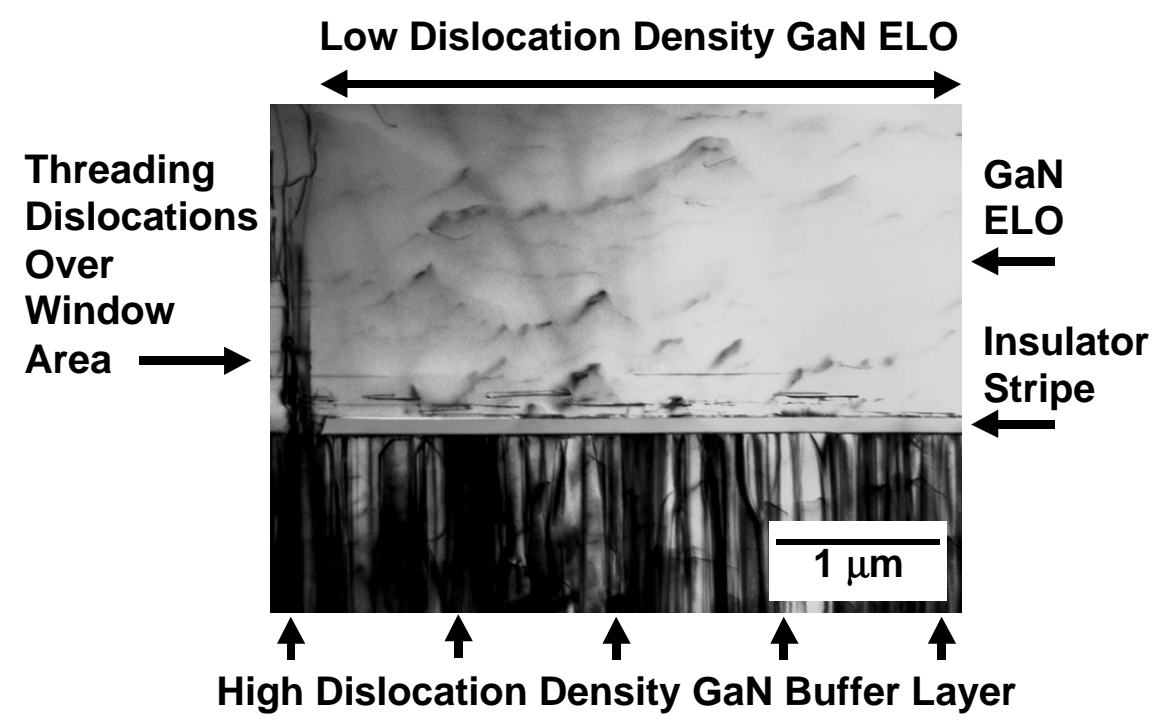

Figure 4. TEM vertical cross-section micrograph of GaN/ELO sample.

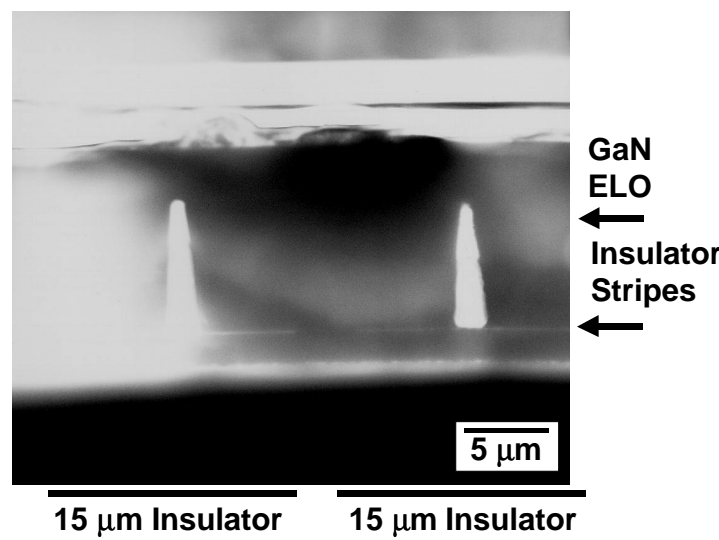

(a)

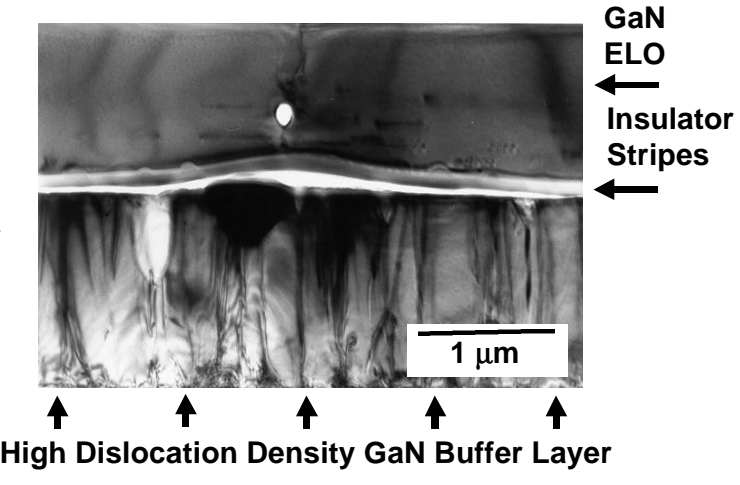

(b)

Figure 5. (a) GaN/ELO with vertical sidewalls ( $\{11 \overline{2} 0\}$ planes); (b) GaN/ELO with inclined sidewalls ( $\{1 \overline{1} 01\}$ planes $)$

respectively. In the case of ELO growth at $1120{ }^{\circ} \mathrm{C}$, which proceeds with vertical sidewalls, there are large voids formed at the centers of the insulator stripes (white triangles in Figure 5(a). This is similar to the void structure reported by Nakamura [20]. In contrast, the void structure for ELO growth at $1080{ }^{\circ} \mathrm{C}$ consist of only a small ( $100 \mathrm{~nm}$ diameter) circular hole immediately above the insulator stripe as shown in Figure 5(b). It should be emphasized that both types of depositions produce ELO have little or no threading dislocations.

Note also in Figure 5(b) that the insulator stripe $\left(\mathrm{SiO}_{2}\right.$ in this case) appears to be buckled near the center of the micrograph and no longer makes intimate contact with the GaN buffer layer below the stripe. This phenomenon was seen in several ELO samples using $\mathrm{SiO}_{2}$ stripes and becomes more problematic for high temperature ELO growth. The use of $\mathrm{SiN}_{\mathrm{x}}$ stripes eliminated this problem as is illustrated in Figure 4 and Figure 5(a).

Double-layer ELO samples were also prepared by rotating the substrate by 60 degrees, such that a second set of insulator stripes were fabricated along another equivalent [1 $\overline{1} 00]$ direction. This resulted in additional dislocation reduction within the areas of the windows of the first ELO 
layer. This dislocation reduction is illustrated in Figure 6, where monochromatic images of the near bandedge CL emission at $364 \mathrm{~nm}$ is shown for each ELO layer.

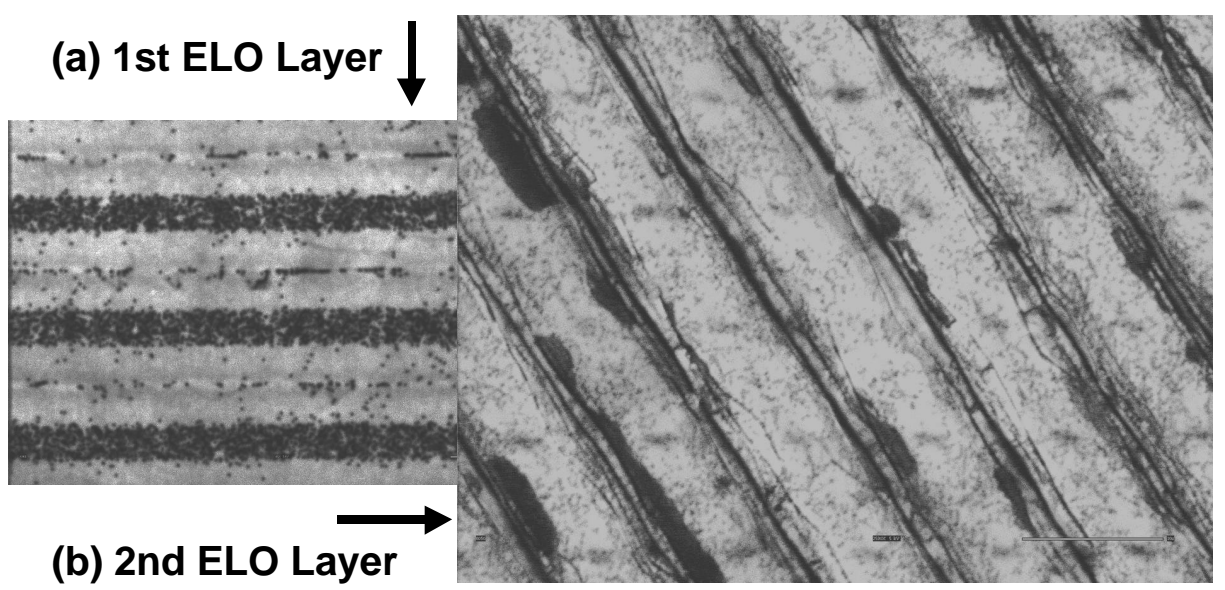

Figure 6. Monochromatic CL emission at $364 \mathrm{~nm}$ for double-layer ELO sample.

\section{REFERENCES}

1. F. A. Ponce, MRS Bulletin 22 (1997) 51.

2. S. Nakamura, T. Mukai, M. Senoh, Appl. Phys. Lett. 64 (1994) 1687.

3. S. Nakamura, M. Senoh, N. Iwasa, S. Nagahama, App. Phys. Lett. 67 (1995) 1868.

4. S. Nakamura, M. Senoh, S. Nagahama, N. Iwasa, T. Yamada, T. Matsushita, Y. Sugimoto, H. Kiyoku, Appl. Phys. Lett. 70 (1995) 1417.

5. S. Nakamura and G. Fasol, The Blue Laser Diode (Springer-Verlag: Heidelberg) (1997).

6. J. Edmond, H.S. Kong, M. Leonard, G. Bulman, G. Negley, Inst. of Phys. Conf. Series 142, (1996).

7. I. Akasaki, S. Sota, H. Sakai, T. Tanaka, M. Koike, H. Amano, Electronics Lett. 32(12), (1996) 1105.

8. G.E. Bulman, K. Doverspike, S.T. Sheppard, T.W. Weeks, H.S. Kong, H.M. Dieringer, J.A. Edmond, J.D. Brown, J.T. Swindell, J.F. Schetzina, Electron. Lett. 33 (1997) 1556.

9. M.P. Mack, A. Abare, M. Aizcorbe, P. Kosokoy, S. Keller, U.K. Mishra, L. Coldren, S. DenBaars, MRS Internet J. Nitride Semicond. Res. 2 (1997) 41.

10. T. Detchprohm, T. Kuroda, K. Hiramatsu, N. Sawaki, H. Goto, Inst. of Phys. Conf. Series 142 (1996) 859.

11. A. Usui, H Sunakawa, A. Sakai, A.A. Yamaguchi, Jpn. J. Appl. Phys. 36 (1997) L899.

12. D. Kapolnek, S. Keller, R. Vetury, R.D. Underwood, P. Kozodoy, S.P. DenBaars, U.K. Mishra, Appl. Phys. Lett. 71 (1997) 1204.

13. A Sakai, H Sunakawa, A Usui, Appl. Phys. Lett. 71 (1997) 2259.

14. Zhonghai Yu, M.A.L. Johnson, T. McNulty, J.D. Brown, J.W. Cook, Jr. and J.F. Schetzina, MRS Internet J. Nitride Semicond. Res. 3 (1998) 6.

15. J. Park, P.A. Grudowski, C.J. Eiting, and R.D. Dupuis, Appl. Phys. Lett. 73, 333 (1998).

16. X. Li,m S.G. Bishop, and J.J. Coleman, Appl. Phys. Lett. 73. 1179 (1998).

17. O Nam, M.D. Bremser, B.L. Ward, R.J. Nemanich, R.F. Davis, Jpn. J. Appl. Phys. 36 (1997) L532.

18. Tsvetanka S. Zheleva, Ok-Hyun Nam, Micheal D. Bremser, Robert F. Davis, Appl. Phys. Lett. 71 (1997) 2472.

19. O-H Nam, MD Bremser, TS Zheleva, RF Davis, Appl. Phys. Lett. 71 (1997) 2638.

20. S. Nakamura, M. Senoh, S. Nagahama, N. Iwasa, T. Yamada, T. Matsushita, H. Kiyoku, Y. Sugimoto, T. Kozaki, H. Umemoto, M. Sano, K. Chocho, Appl. Phys. Lett. 72 (1998) 211. 